\title{
Review: primary prevention strategies do not improve contraceptive use or reduce pregnancies in adolescents
}

Sources of funding: National Health

Research Development

Program, Health

Canada; Ontario

Ministry of Health and

Long-Term Care;

Region of

Social and Public

Health Services

PHRED Program.

Abstract also appears

in Evidence-Based

Nursing.

For correspondence:

Dr A DiCenso, School

University, Hamilton,

Ontario, Canada.

dicensoa@mcmaster.ca
Hamilton-Wentworth

of Nursing, McMaster

DiCenso A, Guyatt G, Willan A, et al. Interventions to reduce unintended pregnancies among adolescents: systematic review of randomised controlled trials. BMJ 2002;324:1426-30.

\section{QUESTION: Do primary prevention strategies delay sexual intercourse, improve use of contraception, and reduce unintended pregnancies in adolescents?}

\section{Data sources}

Published and unpublished studies from 1970-2000 were identified by searching CATLINE, CINAHL, Conference Papers Index, Dissertation Abstracts Online, EMBASE/Excerpta Medica, ERIC, Medline, NTIS, POPLINE, PsycINFO, Sociological Abstracts, and the Cochrane Controlled Trials Register; handsearching 10 key journals (1993-2000); reviewing the bibliographies of retrieved articles; and contacting experts.

\section{Study selection}

Randomised controlled trials (RCTs) in any language were included if they assessed the effects of pregnancy prevention programmes for adolescents $(11-18$ y) on
Primary prevention strategy $v$ control (alternate intervention or nothing) for adolescents*

\begin{tabular}{|c|c|c|c|c|}
\hline \multirow[b]{2}{*}{ Outcomes } & \multirow[b]{2}{*}{$\begin{array}{l}\text { Number of } \\
\text { trials }\end{array}$} & \multicolumn{2}{|c|}{ Weighted event rates } & \multirow[b]{2}{*}{$\begin{array}{l}\text { Pooled odds ratio } \\
\text { (OR) }(95 \% \mathrm{CI})\end{array}$} \\
\hline & & $\begin{array}{l}\text { Primary } \\
\text { prevention }\end{array}$ & Control & \\
\hline \multicolumn{5}{|l|}{ Women } \\
\hline Delayed intercourse & $13(n=9642)$ & $22 \%$ & $20 \%$ & $1.12(0.96$ to 1.30$)$ \\
\hline $\begin{array}{l}\text { Used contraception at } \\
\text { every intercourse }\end{array}$ & $8(n=1967)$ & $45 \%$ & $44 \%$ & $0.95(0.69$ to 1.30$)$ \\
\hline $\begin{array}{l}\text { Used contraception at } \\
\text { last intercourse }\end{array}$ & $5(n=799)$ & $50 \%$ & $46 \%$ & $1.05(0.50$ to 2.19$) \ddagger$ \\
\hline Pregnancy & $12(n=8019)$ & $4.4 \%$ & $4.8 \%$ & $1.04(0.78$ to 1.40$)$ \\
\hline \multicolumn{5}{|l|}{ Men } \\
\hline Delayed intercourse & $11(n=7418)$ & $29 \%$ & $30 \%$ & $0.99(0.84$ to 1.16$)$ \\
\hline $\begin{array}{l}\text { Used contraception at } \\
\text { every intercourse }\end{array}$ & $3(n=1505)$ & $36 \%$ & $38 \%$ & $0.90(0.70$ to 1.16$)$ \\
\hline $\begin{array}{l}\text { Used contraception at } \\
\text { last intercourse }\end{array}$ & $4(n=1262)$ & $69 \%$ & $64 \%$ & 1.25 (0.99 to 1.59$)$ \\
\hline Pregnancy in partners & $5(n=3759)$ & $3.4 \%$ & $2.4 \%$ & $1.54(1.03$ to 2.29$) \S$ \\
\hline
\end{tabular}

*Abbrive 5 (n-3759) $3.4 \%$ from 2-54 months. †For intercourse and pregnancy outcomes, OR $<1.0$ favours intervention; for contraception outcomes, OR $>1.0$ favours intervention. ¥Significant heterogeneity among trials. §Statistically significant. initiation of sexual intercourse, use of birth control, or unintended pregnancy. Prevention programmes included sex education classes, school based clinics, family planning clinics, and community based programmes. Studies were excluded if the interventions were offered in colleges or universities, were designed to prevent a second pregnancy, or if outcomes were only knowledge and attitudes, only condom use, or only births.

\section{Data extraction}

Data were extracted on setting, participants, unit of randomisation and analysis, theoretical framework, intervention, outcomes, length of follow up, proportion followed up, and findings at last follow up by gender. Methodological quality of individual studies was assessed.

\section{Main results}

22 reports of 26 RCTs met the selection criteria (17 published, 5 unpublished). 10 studies randomised clusters such as classrooms, schools, agencies, or neighbourhoods rather than individuals. 18 studies were judged to have poor quality ( $\leq 2$ out of 4 on the modified Jadad scale). Meta-analyses using a random effects model showed that primary prevention programmes did not delay initiation of sexual intercourse in women or men (table), did not improve use of contraception at every intercourse or at last intercourse in women or men (table), did not reduce pregnancy rates in women, and actually increased reported pregnancies in partners of men (table).

\section{Conclusion}

No primary prevention strategies evaluated to date delay initiation of sexual intercourse or improve contraceptive use in adolescent women and men, or reduce pregnancy rates.

\section{COMMENTARY}

We know that a variety of health interventions can change youth attitudes and knowledge. More controversial is whether such interventions can change complex sexual behaviors such as delaying sexual initiation or increasing contraceptive use. The most important question, however, is whether the interventions can affect biological outcomes such as unintended pregnancy or sexually transmitted infections by changing behaviour.

The systematic review by DiCenso et al found that primary prevention strategies did not delay initiation of intercourse, improve contraceptive use among young men and women, or reduce pregnancies in young women. Why do these interventions appear so ineffective? Firstly, a paucity of high quality trials have been published. Only 2 of the studies met all 4 of the authors' quality criteria. Secondly, because every study did not systematically examine each of the key dependent variables, the comparisons are sporadic at best. Thirdly, the heterogeneity of the specific interventions presents difficulties in analysis and interpretation. Some interventions lasted 3 months, whereas others lasted 3 years. Fourthly, the study populations were quite different. Some studies included only sexually active youth, whereas others included both virginal and sexually experienced youth. An accurate assessment of exposure to pregnancy risk is important; that is, we need to know whether youth were sexually active after the intervention.

The current evidence is insufficient to show that any pregnancy prevention intervention definitively affects behaviour or biological outcomes. We need improvements in conceptualising the problem, implementing the interventions, designing the evaluation, and analysing the data. In an ideal study, the intervention would be clearly defined and would target youth before they become sexually active. The samples would be large and include both men and women from a range of income and ethnic groups. Study outcomes would be assessed over a period of years, and would include pregnancies and births, as well as programme costs. Given the political, bureaucratic, and resource limitations of research involving youth, it is doubtful that such a Rolls Royce approach is feasible or affordable. However, this is the type of information needed to show whether adolescent reproductive behaviours can be changed.

Willard Cates Jr, MD, PhD and Nancy E Williamson, $\mathrm{PhD}$ Institute for Family Health, Family Health International Research Triangle Park, North Carolina, USA 